\title{
Tissue Expression of Melanoma-associated Antigen A6 and Clinical Characteristics of Gastric Cancer
}

\author{
MIYO ENDO ${ }^{1}$, MITSURO KANDA $^{1}$, KOICHI SAWAKI ${ }^{1}$, DAI SHIMIZU ${ }^{1}$, CHIE TANAKA $^{1}$, \\ DAISUKE KOBAYASHI ${ }^{1}$, NORIFUMI HATTORI ${ }^{1}$, MASAMICHI HAYASHI ${ }^{1}$, \\ SUGURU YAMADA ${ }^{1}$, MASAHIKO KOIKE ${ }^{1}$, KENJI OMAE ${ }^{2}$ and YASUHIRO KODERA ${ }^{1}$ \\ ${ }^{1}$ Department of Gastroenterological Surgery (Surgery II), \\ Nagoya University Graduate School of Medicine, Nagoya, Japan; \\ ${ }^{2}$ Department of Innovative Research and Education for Clinicians and Trainees (DiRECT), \\ Fukushima Medical University Hospital, Fukushima, Japan
}

\begin{abstract}
Background: Gastric cancer (GC) exhibits heterogeneous clinical and molecular features, requiring the development of new biomarkers to further understand this disease. Our transcriptomic analysis detected overexpression of melanoma-associated antigen A6 (MAGEA6) in metastatic $G C$, leading us to determine the clinical significance of MAGEA6 in GC. Materials and Methods: Fourteen GC cell lines and 230 pairs of surgically resected gastric tissues were subjected to mRNA expression analysis. Polymerase chain reaction array analysis was performed to identify coordinately expressed cancer-related genes, and immunohistochemistry (IHC) was used to detected MAGEA6 expression in situ. Results: MAGEA6 mRNA levels were positively correlated with the expression of matrix metallopeptidase 9 mRNA. MAGEA6 $m R N A$ levels were higher in GC tissues compared with those in normal adjacent tissues. Patients with high MAGEA6 expression had significantly worse prognosis. MAGEA6 protein levels in primary lesions predicted the likelihood of recurrence. Conclusion: Overexpression of MAGEA6 in GC tissues represents a promising biomarker for assessing the malignant phenotype of $G C$.
\end{abstract}

Gastric cancer (GC) is the third leading cause of cancerrelated death worldwide (1). GC is difficult to treat because

This article is freely accessible online.

Correspondence to: Mitsuro Kanda, Nagoya University Graduate School of Medicine, Department of Gastroenterological Surgery (Surgery II), 65 Tsurumai-cho, Showa-ku, Nagoya 466-8550, Japan. Tel: +81 527442249, Fax: +81 527442252, e-mail: m-kanda@med.nagoyau.ac.jp

Key Words: Gastric cancer, MAGE family member A6, expression, biomarker, immunohistochemistry. of its clinical and molecular heterogeneity (2-4). Thus, identification of novel GC-related molecules is critical for developing biomarkers that will enable physicians to improve postoperative clinical care. Despite the use of microarrays and next-generation sequencing to characterize the genomes of cancer cells in order to better understand the initiation and progression of cancer, our knowledge of the clinical significance of individual genes that impart the malignant phenotype to gastric cells is insufficient $(5,6)$. We therefore aimed to identify genes involved in the progression of GC.

For this purpose, we conducted transcriptomic analysis of GC tissues and detected overexpression of the gene encoding melanoma-associated antigen 6 (MAGEA6) in primary tumor tissues of patients with metastatic GC. MAGEA6 resides on the human $\mathrm{X}$ chromosome and encodes a cancer-testis antigen which functions as a ubiquitin ligase physiologically $(7,8)$. MAGEA6 is overexpressed in melanomas, head and neck squamous cell carcinomas, lung carcinomas, and breast carcinomas (9-11). However, to the best of our knowledge, there are no reports focusing on MAGEA6 expression in gastroenterological malignancies, including GC.

Here we focused on MAGEA6, because transcriptome analysis identified it as a candidate molecular marker of GC that may facilitate metastasis and many be associated with adverse outcomes. We therefore evaluated the clinical significance of the expression of MAGEA6 in GC tissues.

\section{Materials and Methods}

Transcriptomic analysis. To identify candidate genes associated with metastatic potential of GC cells, surgically resected gastric tissues from four patients with metastatic GC were subjected to transcriptomic analysis. Global expression profiling was conducted using the HiSeq platform (Illumia, San Diego, CA, USA) to compare the expression levels of 57,749 genes in metastatic GC tissues to those of the corresponding noncancerous adjacent gastric mucosa (12). The four patients had one or two metastatic lesions 
confined in the unilateral robe of the liver but no other distant metastases (e.g. lung, bone, brain, peritoneal and distant lymph nodes) and received the sufficient information necessary to give informed consent before surgery.

Sample collection. The GC cell lines AGS, GCIY, IM95, KATO3, MKN1, MKN7, MKN45, MKN74, N87, NUGC2, NUGC3, NUGC4, OCUM1, and SC6JCK were obtained from the American Type Culture Collection (Manassas, VA, USA) or the Japanese Collection of Research Bioresources Cell Bank (Osaka, Japan). A control, nontumorigenic human epithelial cell line (FHs74) derived from the small intestine was purchased from the American Type Culture Collection. The cell lines were cultured in RPMI-1640 medium supplemented with $10 \%$ fetal bovine serum in an atmosphere containing $5 \% \mathrm{CO}_{2}$ at $37^{\circ} \mathrm{C}$. Primary $\mathrm{GC}$ tissues and corresponding normal adjacent tissues were collected from 230 patients undergoing curative gastric resection for GC without neoadjuvant therapy at Nagoya University Hospital between 2001 and 2014. Written informed consent for use of clinical samples and data, as required by the Institutional Review Board of Nagoya University, was obtained from all patients. The tissue samples were immediately flash-frozen in liquid nitrogen and stored at $-80^{\circ} \mathrm{C}$. A portion (approximately $5 \mathrm{~mm}^{2}$ ) of each tumor sample without necrotic tissue with $>80 \%$ tumor cells was extracted for analysis. Corresponding normal adjacent gastric mucosa $>5 \mathrm{~cm}$ from the edge of the tumor was obtained from the same patient. The eighth edition of the Union for International Cancer Control (UICC) classification was used for pathological staging (13). Since 2006, adjuvant chemotherapy using S-1 (an oral fluorinated pyrimidine) was administered to all patients with UICC stage II-III GC, unless contraindicated by the patient's condition (14). For external validation, a subset (325 patients) included in The Cancer Genome Atlas (TCGA) database was used (15).

Real-time quantitative reverse transcription PCR (RT-PCR) and PCR array analysis. The MAGEA6 mRNA levels of cell lines and tissue samples were analyzed using RT-PCR with an ABI StepOnePlus Real-Time PCR System (Applied Biosystems, Foster City, CA, USA) as previously described. A 94 base-pair product was amplified using the primers as follows: sense, 5'-CCACTGGCAGATCTTCTCCT-3' in exon 1 and antisense 5'-AGGCTCGGTGAGGAGGC-3' in exon 2. The level of glyceraldehyde-3-phosphate dehydrogenase $(G A P D H)$ mRNA was determined as an internal standard, and the expression level of each sample was calculated as the value of MAGEA6 mRNA divided by that of GAPDH mRNA (16). The expression levels of 84 key genes was analyzed using the Human Epithelial to Mesenchymal Transition (EMT) RT Profiler PCR Array (Qiagen, Hilden, Germany) $(17,18)$.

Immunohistochemistry (IHC). Among 230 patients with GC, we selected 88 representative cases who had well-preserved sections for analysis of MAGEA6 protein expression in GC tissues. MAGEA6 protein expression was determined using IHC with a rabbit polyclonal antibody against MAGEA6 (14602-1-AP; Proteintech, Chicago, IL, USA), diluted 1:100 in antibody diluent (Dako, Glostrup, Denmark). The patterns of MAGEA6 expression were graded depending on the percentage of stained cells as follows: $0-10 \%$ : No staining; $10-40 \%$ : weak staining; or $40-100 \%$ : strong staining (19). To avoid subjectivity, the specimens were randomized and coded before analysis by two independent observers uninformed as to the status of the samples (20). Each observer evaluated all specimens at least twice to minimize variations (21).

Statistical analyses. The quantitative Mann-Whitney test and qualitative chi-squared test were employed to compare the differences between groups. The strength of a correlation between two variables was assessed using Spearman's rank correlation coefficient. Overall and disease-free survival rates were calculated using the Kaplan-Meier method. To determine the hazard ratio (HR) for survival associated with each variable, the univariate Cox proportional hazards model was used. Multivariate regression analysis was performed to detect prognostic factors using the Cox proportional hazards model, and variables with values of $p<0.05$ were entered into the final model. All statistical analyses were performed using JMP 14 software (SAS Institute Inc., Cary, NC, USA). Values of $p<0.05$ were considered significant.

Ethics approval and consent to participate. All procedures performed were in accordance with the ethical standards of the responsible committee on human experimentation (institutional and national) and with the Helsinki Declaration of 1964 and later versions. This study was approved by the Institutional Review Board of Nagoya University (approval number 2017-0475) and written informed consent for surgery and usage of clinical data was obtained from all participants.

\section{Results}

Identification of MAGEA6 as a candidate GC-related gene. Transcriptome analysis identified 42 candidate genes that were overexpressed $(\log 2$ ratio $\geq 3)$ in metastatic and GC tissues compared with the corresponding normal tissues, and expressed at comparable levels in GC and metastatic tissues. We conducted a literature review of these genes and selected $M A G E A 6$ for subsequent analyses because MAGEA6 mRNA levels are found to be highest in metastatic tissues, and data on the role of MAGEA6 in GC were unavailable.

Expression of MAGEA6 and genes that encode potentially interacting proteins. The levels of MAGEA6 mRNA were $>10$ fold higher in the GC cell lines GCIY, IM95, KATO3, MKN1, MKN7, MKN45, MKN74, NUGC3, OCUM1 and SC6JCK compared with control FHs74s cells (Figure 1A). MAGEA6 mRNA levels did not differ according to the extent of differentiation of the GC cell lines. PCR array analysis revealed that expression of MAGEA6 was significantly positively correlated with that of the epithelial-mesenchyme transition (EMT)-related gene encoding matrix metallopeptidase 9 (MMP9), with a correlation coefficient of 0.675 (Figure 1B).

Patient characteristics. Patients' ages ranged from 26 to 96 years (mean \pm standard deviation $=66.3 \pm 10.8$ years), and the male:female ratio was 2.54:1. Patients were diagnosed with undifferentiated GC (poorly differentiated adenocarcinoma, signet ring cell carcinoma and mucinous carcinoma) $(n=131)$ 
A

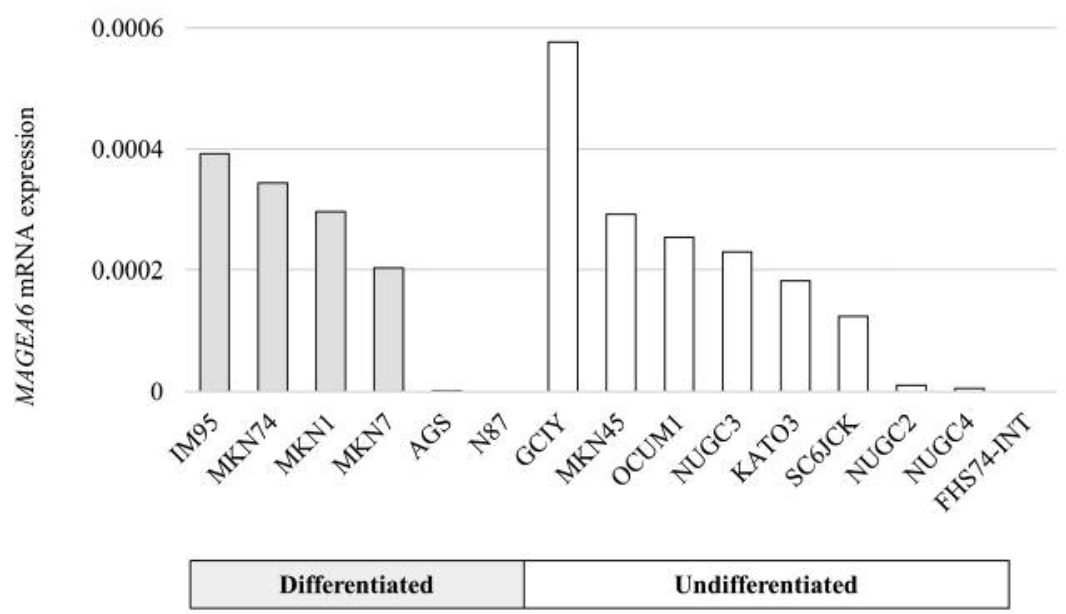

B

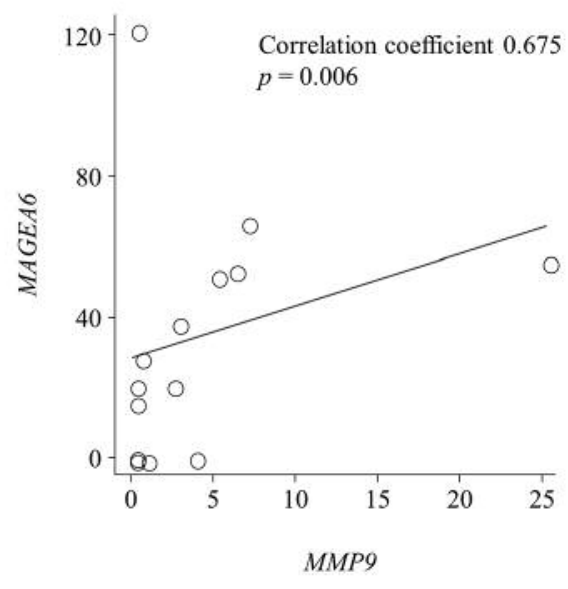

Figure 1. Expression of melanoma-associated antigen A6 (MAGEA6) mRNA in gastric cell lines. A: Differential and elevated mRNA expression was detected in cell lines compared with control FHs74 cells. B: Correlation analysis of the mRNA levels of MAGEA6 and matrix metallopeptidase 9 (MMP9).

or with differentiated GC (papillary, well differentiated and moderately differentiated adenocarcinoma) $(n=99)$. When categorized according to tumor location, 8, 61, 80, and 81 patients had tumors in the entire, upper-third, middle-third, or lower-third of the stomach. According to the eighth edition of the UICC classification, 50, 71, and 109 patients had pathological stages I, II, and III, respectively (Table I).

Expression of MAGEA6 $\mathrm{mRNA}$ in clinical gastric samples and the TCGA cohort. Analysis of 230 pairs of our institutional collection of gastric tissues detected an increase in the levels of MAGEA6 mRNA in GC tissues compared with the corresponding normal adjacent tissues. Consistent with this finding, MAGEA6 mRNA levels were higher in GC tissues compared with paired noncancerous tissues in the external-validation TCGA cohort (Figure 2A).

Patients were stratified into groups with high or low level of MAGEA6 mRNA in cancer tissues compared with the median values of the institutional and TCGA cohorts. A high MAGEA6 level in GC tissues was significantly associated with advanced age and undifferentiated tumor (Table I). Patients in the high MAGEA6 group were more likely to experience shorter overall survival compared with those in the low MAGEA6 group (5-year survival rates of $71 \%$ and $86 \%$, respectively, $p=0.023$ ) in the institutional cohort. Similarly, in the external-validation TCGA cohort, the overall survival of the high MAGEA6 group was significantly shorter compared with that of the low MAGEA6 group (5year survival rates of $30 \%$ and $46 \%$, respectively, $p=0.029$ ) (Figure 2B). Multivariate analysis of the institutional cohort identified high MAGEA6 expression as an independent prognostic factor for overall survival after curative gastrectomy (hazard ratio $=2.26 ; 95 \%$ confidence interval $=1.17-4.37, p=0.015$ ) (Table II).

We next evaluated the correlation between MAGEA6 expression and disease recurrence. The group with high MAGEA6 experienced significantly shorter disease-free survival compared with that with low MAGEA6 expression (2-year survival rate of $69 \%$ and $85 \%$, respectively, $p=0.025$ ) (Figure 2C). The overall incidence of recurrence was significantly higher in the high MAGEA6 group than that in the low MAGEA6 group (32\% and $18 \%$, respectively, $p=0.015$ ); however, no significant difference was observed in the first incidence of peritoneal, hematogenous, or lymph node recurrence (Figure 2D).

Association between MAGEA6 protein expression and disease recurrence. Patients with stage I-III GC were classified into groups with no, weak, or strong staining of MAGEA6 in tissue sections (Figure 3A). The frequency of recurrence after gastrectomy gradually increased with increased staining intensity (Figure 3B), indicating that MAGEA6 expression was useful for risk stratification of recurrence after curative gastrectomy.

\section{Discussion}

With the aim of identifying a novel molecule related to the progression of GC, we conducted global expression analysis using tissues from patients with metastatic GC. We found 
that MAGEA6 was highly expressed in primary and metastatic lesions of GC compared with the corresponding, uninvolved gastric tissues. The level of MAGEA6 mRNA was increased in $71 \%(n=14)$ of GC cell lines and correlated with $M M P 9$. In the independent institutional and TCGA cohorts, high MAGEA6 expression in GC tissues was significantly associated with shortened overall and diseasefree survival. Moreover, we found that MAGEA6 expression in situ correlated with risk of postoperative recurrence after gastrectomy.

MAGEA6 is normally expressed in the testis and specifically overexpressed in cancer cells; however, its physiological and pathological functions are largely unknown (9, 10, 22). Moreover, MAGEA6 functions as a cancerspecific ubiquitin ligase which ubiquitinates and degrades AMP-activated protein kinase (AMPK), which plays a pivotal role in cell metabolism $(11,23)$. For example, MAGEA6 is specifically expressed in cancerous tissues and cancer cell lines $(10,24)$. Knockdown of MAGEA6 in renal carcinoma cells induced the stabilization and activation of AMPK $\alpha 1$, leading to apoptotic cell death (11). Furthermore, inhibition of MAGEA6 expression reduced tumorigenicity in mouse subcutaneous xenograft models of cancer. These findings inspired us to investigate MAGEA6 expression in GC (11).

There is no evidence that MAGEA6 contributes to the mechanism that promotes metastasis of GC cells. Therefore, we performed PCR array analysis to identify cancer-related genes expressed coordinately with MAGEA6 with the aim of acquiring evidence to implicate MAGEA6 in cancer progression. We found that the MMP9 level had the highest correlation coefficient associated with MAGEA6 expression among 84 cancer-related genes. MMPs are a family of zinccontaining proteolytic enzymes that degrade the protein components of the extracellular matrix and endothelial cell basement membrane (25). MMP9 directly induces the EMT as a downstream mediator of transforming growth factor- $\beta 1$, which is required for the initiation and maintenance of EMT (26-28). Although further investigations are required, including pathway analysis and biochemical analyses (e.g. immunoprecipitation and western blotting), this finding supports the possibility of interactions between MAGEA6 and proteins that mediate the EMT and contributes to the understanding of the function of MAGEA6 in GC.

In the expression analysis of clinical gastric tissues, we observed the lack or low abundance of MAGEA6 expression in normal adjacent gastric tissues, consistent with the classification of MAGEA6 as a cancer-testis antigen. Patients with high tissue levels of MAGEA6 mRNA experienced a higher incidence of postoperative recurrence and poorer prognosis, highlighting the potential utility of MAGEA6 expression as a novel biomarker of GC progression. These findings were reproduced by our analysis of the external-validation TCGA dataset (15), supporting the
Table I. Association between the levels of melanoma-associated antigen A6 (MAGEA6) mRNA and clinicopathological parameters of 230 patients with gastric cancer.

\begin{tabular}{|c|c|c|c|}
\hline \multirow[t]{2}{*}{ Variable } & \multicolumn{2}{|c|}{$\begin{array}{c}\text { MAGEA6 mRNA in } \\
\text { GC tissue }(\mathrm{n}=115)\end{array}$} & \multirow[b]{2}{*}{$p$-Value } \\
\hline & High & Low & \\
\hline \multicolumn{4}{|l|}{ Age } \\
\hline$<65$ Years & 42 & 57 & \multirow[t]{2}{*}{0.046} \\
\hline$\geq 65$ Years & 73 & 58 & \\
\hline \multicolumn{4}{|l|}{ Gender } \\
\hline Male & 86 & 79 & \multirow[t]{2}{*}{0.305} \\
\hline Female & 29 & 36 & \\
\hline \multicolumn{4}{|l|}{ Tumor location } \\
\hline Entire & 5 & 3 & \multirow[t]{4}{*}{0.772} \\
\hline Upper third & 28 & 33 & \\
\hline Middle third & 42 & 38 & \\
\hline Lower third & 40 & 41 & \\
\hline \multicolumn{4}{|l|}{ CEA } \\
\hline$\leq 5 \mathrm{ng} / \mathrm{ml}$ & 95 & 100 & \multirow[t]{2}{*}{0.359} \\
\hline$>5 \mathrm{ng} / \mathrm{ml}$ & 20 & 15 & \\
\hline \multicolumn{4}{|l|}{ CA19-9 } \\
\hline$\leq 37 \mathrm{IU} / \mathrm{ml}$ & 96 & 95 & \multirow[t]{2}{*}{0.861} \\
\hline$>37 \mathrm{IU} / \mathrm{ml}$ & 19 & 20 & \\
\hline \multicolumn{4}{|l|}{ Tumor size (mm) } \\
\hline$<50 \mathrm{~mm}$ & 65 & 59 & \multirow[t]{2}{*}{0.427} \\
\hline$\geq 50 \mathrm{~mm}$ & 50 & 56 & \\
\hline \multicolumn{4}{|l|}{ Tumor depth (UICC) } \\
\hline pT1-3 & 74 & 73 & \multirow[t]{2}{*}{0.891} \\
\hline pT4 & 41 & 42 & \\
\hline \multicolumn{4}{|l|}{ Differentiation } \\
\hline Differentiated & 57 & 42 & \multirow[t]{2}{*}{0.046} \\
\hline Undifferentiated & 58 & 73 & \\
\hline \multicolumn{4}{|c|}{ Lymphatic involvement } \\
\hline Absent & 17 & 20 & \multirow[t]{2}{*}{0.590} \\
\hline Present & 98 & 95 & \\
\hline \multicolumn{4}{|l|}{ Vessel invasion } \\
\hline Absent & 41 & 46 & \multirow[t]{2}{*}{0.497} \\
\hline Present & 74 & 69 & \\
\hline \multicolumn{4}{|c|}{ Infiltrative growth type } \\
\hline Invasive growth & 31 & 40 & \multirow[t]{2}{*}{0.199} \\
\hline Expansive growth & 84 & 75 & \\
\hline Lymph node metasta & & & \\
\hline Absent & 38 & 49 & 0.135 \\
\hline Present & 77 & 66 & \\
\hline UICC stage & & & \\
\hline $\mathrm{I}$ & 24 & 26 & 0.950 \\
\hline II & 36 & 35 & \\
\hline III & 55 & 54 & \\
\hline
\end{tabular}

CA19-9: Carbohydrate antigen 19-9; CEA: carcinoembryonic antigen; UICC: Union for International Cancer Control classification, eighth edition (13).

universality and utility of MAGEA6 as a biomarker of diverse populations. However, to translate our results into clinical practice, MAGEA6 expression must be shown to be effective for monitoring postoperative disease and for selecting an optimal multimodal management strategy. 


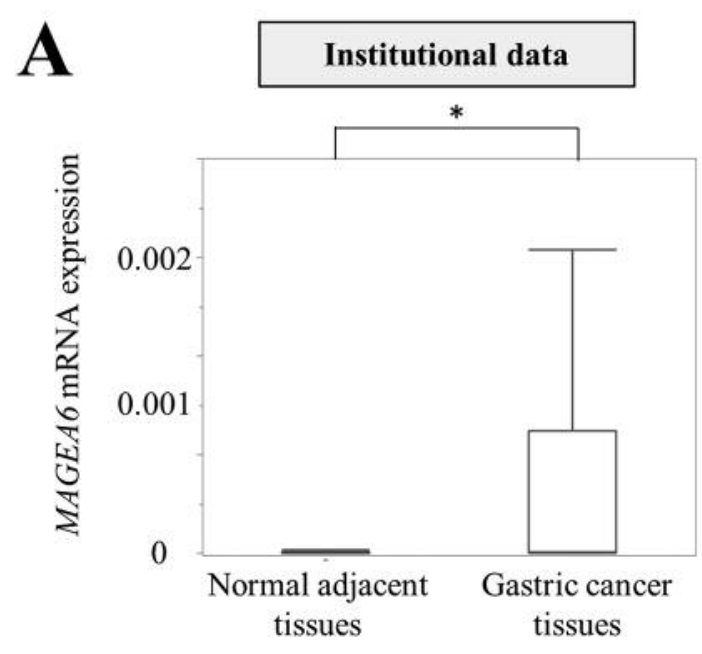

B

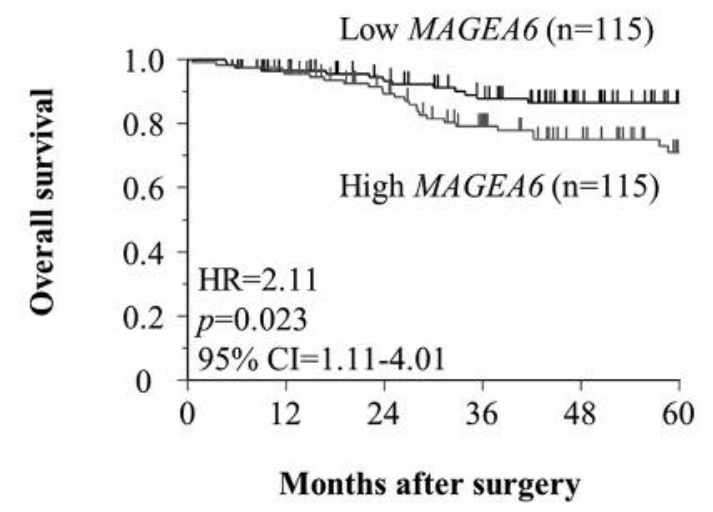

C Institutional data

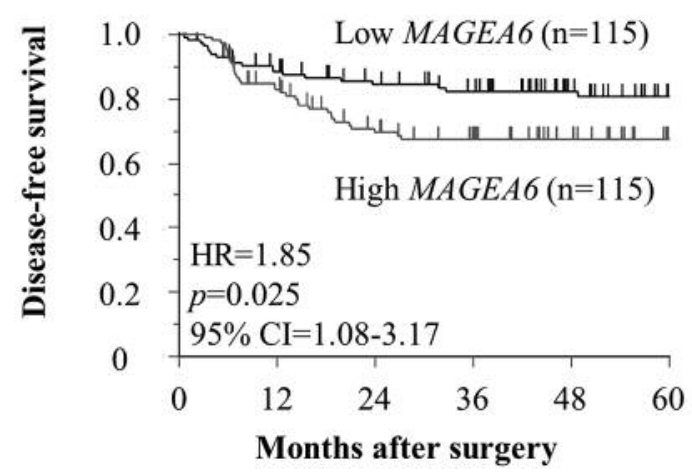

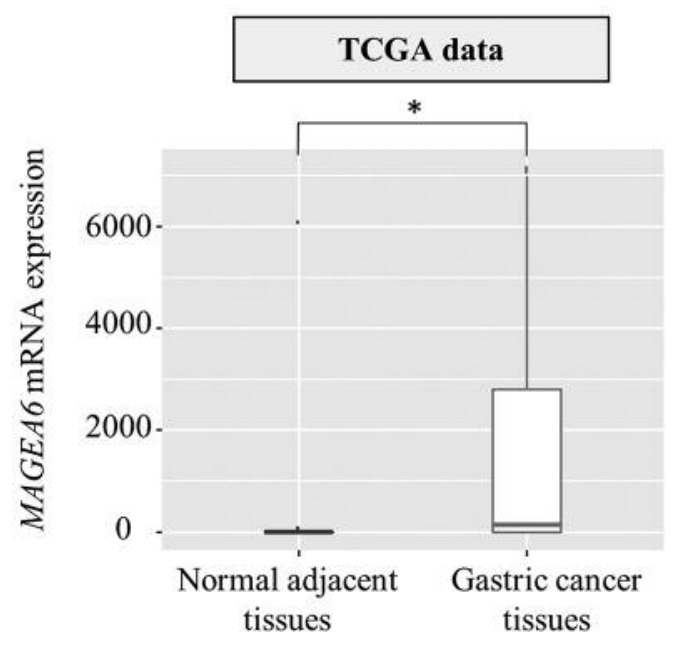

TCGA data

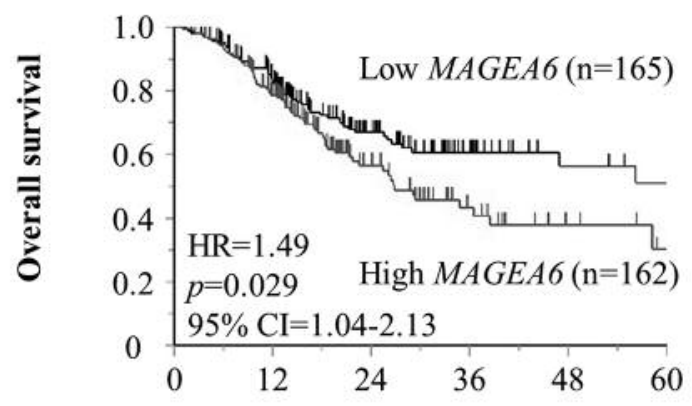

Months after surgery

D

Total Low MAGEA6 पHigh MAGEA6

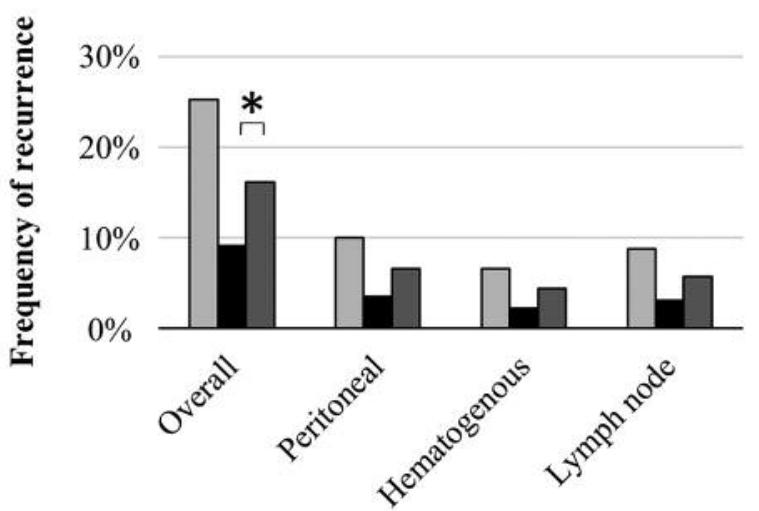

Figure 2. Expression of melanoma-associated antigen A6 (MAGEA6) mRNA in gastric tissues. A: Gastric cancer (GC) tissues expressed significantly higher levels of MAGEA6 mRNA compared with those of the corresponding normal adjacent tissues in the institutional and external-validation The Cancer Genome Atlas (TCGA) cohorts. B: Overall survival of patients with stage I-III GC according to the tissue expression of MAGEA6 mRNA in the institutional and external-validation TCGA cohorts. C: Disease-free survival of patients with stages I-III GC according to the tissue expression of MAGEA6 mRNA. D: Distribution of initial recurrence patterns after gastrectomy according to the level of tissue MAGEA6 mRNA. 

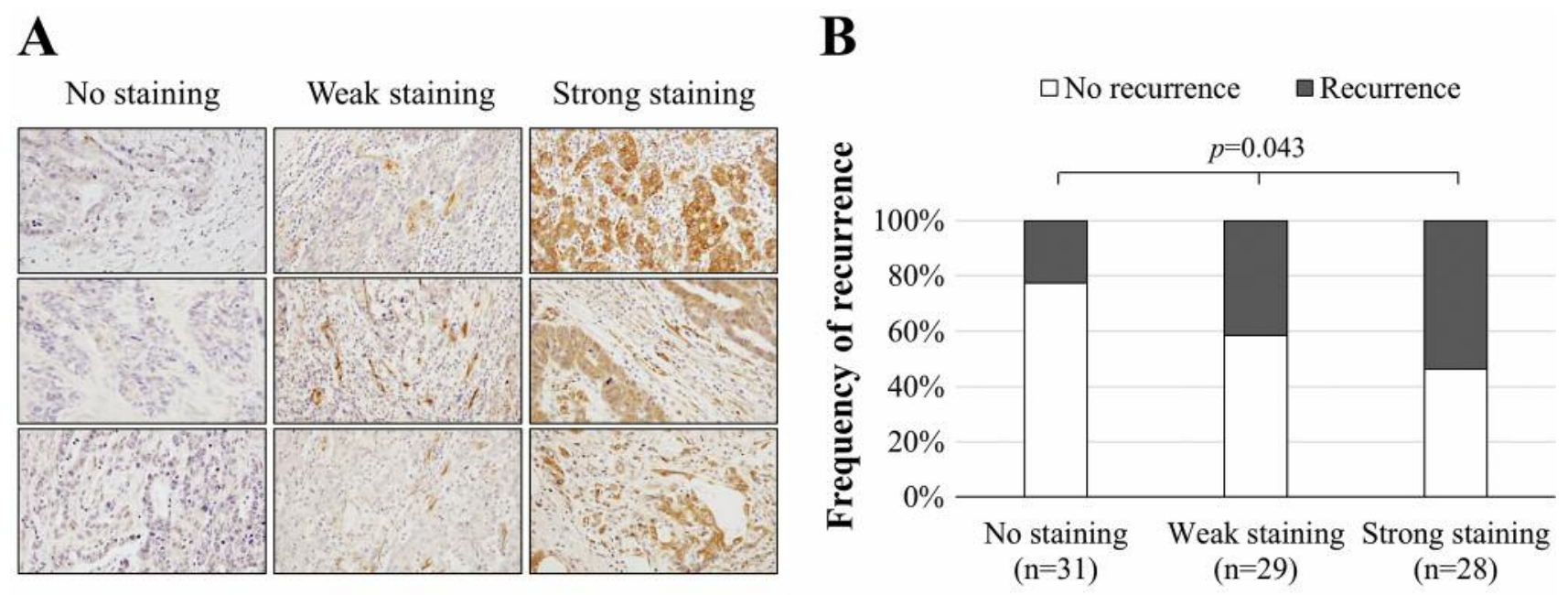

Figure 3. Immunohistochemical analysis of melanoma-associated antigen A6 (MAGEA6) expression. A: Representative examples of MAGEA6 expression: No staining, weak staining, and strong staining. B: Positive correlation was observed between the frequency of recurrence and the staining intensities of MAGEA6 in tissues.

Table II. Prognostic factors of overall survival of 230 patients with gastric cancer.

\begin{tabular}{|c|c|c|c|c|c|c|c|}
\hline \multirow[t]{2}{*}{ Variable } & \multirow[t]{2}{*}{$\mathrm{n}$} & \multicolumn{3}{|c|}{ Univariate } & \multicolumn{3}{|c|}{ Multivariate } \\
\hline & & HR & $95 \% \mathrm{CI}$ & $p$-Value & HR & $95 \% \mathrm{CI}$ & $p$-Value \\
\hline \multicolumn{8}{|l|}{ Age } \\
\hline$\geq 65$ Years & 131 & 1.02 & $0.55-1.87$ & 0.959 & & & \\
\hline \multicolumn{8}{|l|}{ Gender } \\
\hline Female & 65 & 0.95 & $0.48-1.85$ & 0.869 & & & \\
\hline \multicolumn{8}{|l|}{ Tumor location } \\
\hline Distal & 81 & 0.84 & $0.37-1.39$ & 0.356 & & & \\
\hline \multicolumn{8}{|l|}{ CEA } \\
\hline$>5 \mathrm{ng} / \mathrm{ml}$ & 35 & 1.56 & $0.74-3.25$ & 0.241 & & & \\
\hline \multicolumn{8}{|l|}{ CA19-9 } \\
\hline$>37 \mathrm{IU} / \mathrm{ml}$ & 39 & 2.64 & $1.34-5.21$ & 0.005 & 1.80 & $0.89-3.64$ & 0.104 \\
\hline \multicolumn{8}{|l|}{ Tumor size } \\
\hline$\geq 50 \mathrm{~mm}$ & 106 & 3.19 & $1.63-6.23$ & $<0.001$ & 2.52 & $1.27-5.00$ & 0.008 \\
\hline \multicolumn{8}{|c|}{ Tumor depth (UICC) } \\
\hline pT4 & 83 & 3.38 & $1.81-6.31$ & $<0.001$ & 1.70 & $0.84-3.44$ & 0.139 \\
\hline \multicolumn{8}{|c|}{ Tumor differentiation } \\
\hline Undifferentiated & 99 & 1.69 & $0.89-3.21$ & 0.111 & & & \\
\hline \multicolumn{8}{|c|}{ Lymphatic involvement } \\
\hline Yes & 193 & 5.43 & $1.31-22.58$ & 0.020 & 0.65 & $0.12-3.45$ & 0.613 \\
\hline \multicolumn{8}{|l|}{ Vessel invasion } \\
\hline Yes & 143 & 3.74 & $1.73-8.12$ & 0.001 & 1.68 & $0.70-4.04$ & 0.244 \\
\hline \multicolumn{8}{|l|}{ Invasive growth } \\
\hline Yes & 71 & 2.03 & $1.09-3.76$ & 0.025 & 1.57 & $0.77-3.17$ & 0.213 \\
\hline \multicolumn{8}{|c|}{ Lymph node metastasis } \\
\hline Yes & 143 & 12.26 & $3.76-39.97$ & $<0.001$ & 7.37 & $1.90-28.53$ & 0.004 \\
\hline \multicolumn{8}{|l|}{ MAGEA6 expression } \\
\hline High & 115 & 2.10 & $1.12-3.96$ & 0.021 & 2.26 & $1.17-4.37$ & 0.015 \\
\hline
\end{tabular}

CA19-9: Carbohydrate antigen 19-9; CEA: carcinoembryonic antigen; CI: confidence interval; HR: hazard ratio; UICC: Union for International Cancer Control classification, eighth edition (13). 
Another important finding of the current study is that in situ MAGEA6 expression was detected using IHC, which is a standard clinical technique that can readily be applied to archived formalin-fixed paraffin-embedded samples (29-31). Our results indicate that IHC assays for MAGEA6 expression may enable physicians to stratify patients at risk of postoperative recurrence at the time of endoscopic biopsy or surgical resection of the primary GC.

There are some limitations to our current study. Firstly, extensive expression analyses of proteins, particularly those related to the EMT, are desirable to further understand the biological functions of MAGEA6 in GC. Secondly, this study was limited by its relatively small sample size and retrospective nature, although validated by the TCGA cohort. To determine the usefulness of MAGEA6 expression as a biomarker for GC, analysis of a larger cohort using multiple clinical samples such as gastric tissues, ascites fluids and serum samples, will be required to deepen our knowledge of the clinical significance of MAGEA6 expression.

\section{Conclusion}

Tissue expression levels of MAGEA6 mRNA and protein were associated with unfavorable prognosis of patients after curative gastrectomy for GC. A relatively high level of MAGEA6 in GC tissues may represent a promising biomarker of the malignant phenotype of GC.

\section{Conflicts of Interest}

The Authors have no conflicts of interest directly relevant to the content of this article.

\section{Authors' Contributions}

ME, MK and KS conceived the study concept and design, analyzed data and wrote the article. MK, DS, CT, DK, NH, MH, SY, MK, $\mathrm{KO}$ and $\mathrm{YK}$ contributed to data acquisition and interpretation. KO contributed to statistical analysis. DS, CT, DK, NH, MH, SY, MK, $\mathrm{KO}$ revised the draft. All authors have read and approved the final version of the article.

\section{Acknowledgements}

The Authors thank Edanz Group (www.edanzediting.com/ac) for editing a draft of this article.

\section{References}

1 Thrift AP and El-Serag HB: Burden of gastric cancer. Clin Gastroenterol Hepatol, 2019. PMID: 31362118. DOI: 10.1016/j.cgh.2019.07.045

2 Kanda M, Suh YS, Park DJ, Tanaka C, Ahn SH, Kong SH, Lee HJ, Kobayashi D, Fujiwara M, Shimada H, Cho B, Murotani K, Kim HH, Yang HK and Kodera Y: Serum levels of anos1 serve as a diagnostic biomarker of gastric cancer: A prospective multicenter observational study. Gastric Cancer, 2019. PMID: 31377880. DOI: 10.1007/s10120-019-00995-z

3 McLean MH and El-Omar EM: Genetics of gastric cancer. Nat Rev Gastroenterol Hepatol 11(11): 664-674, 2014. PMID: 25134511. DOI: $10.1038 /$ nrgastro.2014.143

4 Van Cutsem E, Sagaert X, Topal B, Haustermans K and Prenen H: Gastric cancer. Lancet 388(10060): 2654-2664, 2016. PMID: 27156933. DOI: 10.1016/S0140-6736(16)30354-3

5 Duraes C, Almeida GM, Seruca R, Oliveira C and Carneiro F: Biomarkers for gastric cancer: Prognostic, predictive or targets of therapy? Virchows Arch 464(3): 367-378, 2014. PMID: 24487788. DOI: 10.1007/s00428-013-1533-y

6 Razzak M: Genetics: New molecular classification of gastric adenocarcinoma proposed by the Cancer Genome Atlas. Nat Rev Clin Oncol 11(9): 499, 2014. PMID: 25113841. DOI: 10.1038/ nrclinonc.2014.138

7 Kanda M, Nomoto S, Oya H, Takami H, Shimizu D, Hibino S, Hashimoto R, Kobayashi D, Tanaka C, Yamada S, Fujii T, Nakayama G, Sugimoto H, Koike M, Fujiwara M and Kodera Y: The expression of melanoma-associated antigen D2 both in surgically resected and serum samples serves as clinically relevant biomarker of gastric cancer progression. Ann Surg Oncol 23(Suppl 2): 214-221, 2016. PMID: 25743330. DOI: 10.1245/s10434-015-4457-8

8 Van Tongelen A, Loriot A and De Smet C: Oncogenic roles of DNA hypomethylation through the activation of cancer-germline genes. Cancer Lett 396: 130-137, 2017. PMID: 28342986. DOI: 10.1016/j.canlet.2017.03.029

9 Kim DD, Yang CS, Chae HD, Kwak SG and Jeon $\mathrm{CH}$ : Melanoma antigen-encoding gene family member A1-6 and hTERT in the detection of circulating tumor cells following CD45(-) depletion and rna extraction. Oncol Lett 14(1): 837843, 2017. PMID: 28693240. DOI: 10.3892/ol.2017.6226

10 Sang M, Wu X, Fan X, Lian Y and Sang M: Mage-A family serves as poor prognostic markers and potential therapeutic targets for epithelial ovarian cancer patients: A retrospective clinical study. Gynecol Endocrinol 33(6): 480-484, 2017. PMID: 28277121. DOI: 10.1080/09513590.2017.1291611

11 Ye X, Xie J, Huang H and Deng Z: Knockdown of MAGEA6 activates amp-activated protein kinase (AMPK) signaling to inhibit human renal cell carcinoma cells. Cell Physiol Biochem 45(3): 1205-1218, 2018. PMID: 29448247. DOI: 10.1159/000487452

12 Kanda M, Tanaka H, Shimizu D, Miwa T, Umeda S, Tanaka C, Kobayashi D, Hattori N, Suenaga M, Hayashi M, Iwata N, Yamada S, Fujiwara M and Kodera Y: SYT7 acts as a driver of hepatic metastasis formation of gastric cancer cells. Oncogene 37(39): 5355-5366, 2018. PMID: 29858600. DOI: 10.1038/s41388-0180335-8

13 Liu JY, Peng CW, Yang XJ, Huang CQ and Li Y: The prognosis role of AJCC/UICC 8(th) edition staging system in gastric cancer, a retrospective analysis. Am J Transl Res 10(1): 292-303, 2018. PMID: 29423014.

14 Kanda M, Murotani K, Kobayashi D, Tanaka C, Yamada S, Fujii T, Nakayama G, Sugimoto H, Koike M, Fujiwara M and Kodera Y: Postoperative adjuvant chemotherapy with S-1 alters recurrence patterns and prognostic factors among patients with stage II/III gastric cancer: A propensity score matching analysis. Surgery 158(6): 1573-1580, 2015. PMID: 26120068. DOI: 10.1016/j.surg.2015.05.017 
15 The Cancer Genome Atlas Research Network: Comprehensive molecular characterization of gastric adenocarcinoma. Nature 513(7517): 202-209, 2014. PMID: 25079317. DOI: 10.1038/ nature 13480

16 Nakanishi K, Kanda M, Umeda S, Tanaka C, Kobayashi D, Hayashi M, Yamada S and Kodera Y: The levels of SYT13 and CEA mRNAs in peritoneal lavages predict the peritoneal recurrence of gastric cancer. Gastric Cancer, 2019. PMID: 31055693. DOI: 10.1007/s10120-019-00967-3

17 Tanaka H, Kanda M, Miwa T, Tanaka C, Kobayashi D, Umeda S, Shibata M, Suenaga M, Hattori N, Hayashi M, Iwata N, Yamada S, Nakayama G, Fujiwara M and Kodera Y: Patternspecific transcriptomics identifies ASGR2 as a predictor of hematogenous recurrence of gastric cancer. Mol Cancer Res 16(9): 1420-1429, 2018. PMID: 31055693. DOI: 10.1158/15417786.Mcr-17-0467

18 Kanda M, Shimizu D, Tanaka H, Tanaka C, Kobayashi D, Hayashi M, Takami H, Niwa Y, Yamada S, Fujii T, Sugimoto H and Kodera Y: Synaptotagmin XIII expression and peritoneal metastasis in gastric cancer. Br J Surg 105(10): 1349-1358, 2018. PMID: 29741294. DOI: 10.1002/bjs.10876

19 Pirog EC: Immunohistochemistry and in situ hybridization for the diagnosis and classification of squamous lesions of the anogenital region. Semin Diagn Pathol 32(5): 409-418, 2015. PMID: 25862555. DOI: 10.1053/j.semdp.2015.02.015

20 Sawaki K, Kanda M, Miwa T, Umeda S, Tanaka H, Tanaka C, Kobayashi D, Suenaga M, Hattori N, Hayashi M, Yamada S, Nakayama G, Fujiwara M and Kodera Y: Troponin I2 as a specific biomarker for prediction of peritoneal metastasis in gastric cancer. Ann Surg Oncol 25(7): 2083-2090, 2018. PMID: 29663169. DOI: 10.1245/s10434-018-6480-z

21 Kanda M, Shimizu D, Tanaka H, Tanaka C, Kobayashi D, Hayashi M, Iwata N, Niwa Y, Yamada S, Fujii T, Sugimoto H, Murotani K, Fujiwara M and Kodera Y: Significance of SYT8 for the detection, prediction, and treatment of peritoneal metastasis from gastric cancer. Ann Surg 267(3): 495-503, 2018. PMID: 28026832. DOI: 10.1097/SLA.0000000000002096

22 Bert T, Lubomierski N, Gangsauge S, Munch K, Printz H, Prasnikar N, Robbel C and Simon B: Expression spectrum and methylation-dependent regulation of melanoma antigen-encoding gene family members in pancreatic cancer cells. Pancreatology 2(2): 146-154, 2002. PMID: 12123095. DOI: $10.1159 / 000055905$

23 Garcia D and Shaw RJ: AMPK: Mechanisms of cellular energy sensing and restoration of metabolic balance. Mol Cell 66(6): 789800, 2017. PMID: 28622524. DOI: 10.1016/j.molcel.2017.05.032

24 Germano S, Kennedy S, Rani S, Gleeson G, Clynes M, Doolan P, McDonnell S, Hughes L, Crown J and O'Driscoll L: MAGE$\mathrm{D} 4 \mathrm{~B}$ is a novel marker of poor prognosis and potential therapeutic target involved in breast cancer tumorigenesis. Int $\mathrm{J}$ Cancer 130(9): 1991-2002, 2012. PMID: 21618523. DOI: $10.1002 / \mathrm{ijc} .26200$
25 Bai X, Li YY, Zhang HY, Wang F, He HL, Yao JC, Liu L and Li SS: Role of matrix metalloproteinase-9 in transforming growth factor-beta1-induced epithelial-mesenchymal transition in esophageal squamous cell carcinoma. Onco Targets Ther 10: 2837-2847, 2017. PMID: 28652766. DOI: 10.2147/ott.S134813

26 Joseph MJ, Dangi-Garimella S, Shields MA, Diamond ME, Sun L, Koblinski JE and Munshi HG: Slug is a downstream mediator of transforming growth factor-beta1-induced matrix metalloproteinase-9 expression and invasion of oral cancer cells. J Cell Biochem 108(3): 726-736, 2009. PMID: 19681038. DOI: $10.1002 / \mathrm{jcb} .22309$

27 Sun L, Diamond ME, Ottaviano AJ, Joseph MJ, Ananthanarayan $\mathrm{V}$ and Munshi HG: Transforming growth factor-beta 1 promotes matrix metalloproteinase-9-mediated oral cancer invasion through snail expression. Mol Cancer Res 6(1): 10-20, 2008. PMID: 18234959 . DOI: 10.1158/1541-7786.Mcr-07-0208

28 Orlichenko LS and Radisky DC: Matrix metalloproteinases stimulate epithelial-mesenchymal transition during tumor development. Clin Exp Metastasis 25(6): 593-600, 2008. PMID: 18286378. DOI: $10.1007 / \mathrm{s} 10585-008-9143-9$

29 Loupy A, Hill GS, Suberbielle C, Charron D, Anglicheau D, Zuber J, Timsit MO, Duong JP, Bruneval P, Vernerey D, Empana JP, Jouven X, Nochy D and Legendre CH: Significance of C4D Banff scores in early protocol biopsies of kidney transplant recipients with preformed donor-specific antibodies (DSA). Am J Transplant 11(1): 56-65, 2011. PMID: 21199348. DOI: 10.1111/j.1600-6143.2010.03364.x

30 Magaki S, Hojat SA, Wei B, So A and Yong WH: An introduction to the performance of immunohistochemistry. Methods Mol Biol 1897: 289-298, 2019. PMID: 30539453. DOI: 10.1007/978-1-4939-8935-5_25.

31 Kanda M, Shimizu D, Fujii T, Sueoka S, Tanaka Y, Ezaka K, Takami H, Tanaka H, Hashimoto R, Iwata N, Kobayashi D, Tanaka C, Yamada S, Nakayama G, Sugimoto H, Koike M, Fujiwara $\mathrm{M}$ and Kodera Y: Function and diagnostic value of anosmin-1 in gastric cancer progression. Int $\mathbf{J}$ Cancer 138(3): 721-730, 2016. PMID: 26270236. DOI: 10.1002/ijc.29803 